\title{
QUANTIFICAÇÃO DE RAÍZES FINAS EM UM POVOAMENTO DE Pinus taeda L. E UMA ÁREA DE CAMPO EM CAMBARÁ DO SUL, RS
}

\author{
FINE ROOT QUANTIFICATION IN A Pinus taeda L. STAND AND IN GRASSLAND AREA IN \\ CAMBARÁ DO SUL (RS)
}

Vicente Guilherme Lopes ${ }^{1}$ Mauro Valdir Schumacher ${ }^{2}$ Francine Neves Calil $^{3}$ Marcio Viera $^{4}$ Rudi Witschoreck ${ }^{5}$

\begin{abstract}
RESUMO
Os objetivos do trabalho foram quantificar e comparar a densidade e a biomassa de raízes finas $(\leq 2,0 \mathrm{~mm})$ na serapilheira e nas camadas de $0-10,10-20,20-30,30-40 \mathrm{~cm}$ ao longo do perfil de solo, em um povoamento de Pinus taeda L., com 15 anos de idade, e em uma área de campo adjacente. A obtenção das amostras de raízes, foi realizada partindo da escavação de monolitos. As raízes foram separadas do solo por meio de lavagem e catação e, na sequência, foram distribuídas sobre uma folha de papel branca, em que, com o auxílio de uma câmera digital, foram obtidas imagens. Com o auxilio do software Image Tool for Windows version $3.00 \bigcirc$ as imagens foram processadas para quantificação do comprimento das raízes. Após, as raízes foram secas e, depois, pesadas para determinação da biomassa. A vegetação presente na área de campo apresenta uma densidade de raízes finas $234,28 \%$ maior que a área adjacente onde encontra-se o povoamento de Pinus taeda L.
\end{abstract}

Palavras-chave: Pinus taeda; campo; raízes finas; biomassa.

\begin{abstract}
The objectives of this study were to comparatively quantify length and biomass of fine roots $(\leq 2.0 \mathrm{~mm})$ in the soil profile $(0-10,10-20,20-30,30-40 \mathrm{~cm})$ and in the litter of a 15-year-old Pinus taeda L. stand, as well as in an adjacent Grassland area. The samples were obtained through monolith excavation. Roots were separated through washing and collecting and were then distributed over a white sheet of paper, where images were obtained with a digital camera. Using the software Image Tool for Windows version $3.00 \bigcirc$ the images were processed to quantify root length. Subsequently, roots were dried in a stove and, weighed to determine the biomass. The vegetation in the Grassland area showed $234.28 \%$ greater density of fine roots than the adjacent area where the Pinus taeda L.stand is located.
\end{abstract}

Keywords: Pinus taeda; grass; fine roots; biomass.

1. Engenheiro Florestal, M.Sc., Doutorando do Programa de Pós-graduação em Engenharia Florestal, Centro de Ciências Rurais, Universidade Federal de Santa Maria, Av. Roraima, 1000, CEP 97015-900, Santa Maria (RS). viguilopes@yahoo.com.br

2. Engenheiro Florestal, Dr., Professor do Departamento de Ciências Florestais, Centro de Ciências Rurais, Universidade Federal de Santa Maria, Av. Roraima, 1000, CEP 97015-900, Santa Maria (RS). mvschumacher@pq.cnpq.br

3. Engenheiro Florestal, Dra ${ }^{\mathrm{a}}$, Professora do Curso de Engenharia Florestal, Universidade Federal de Goias, Rua 1024, n. 434, Apto. 303, Quadra 64 - Lote 24/25, Setor Pedro Ludovico, CEP 74823-040, Goiânia (GO). francine.calil@terra.com.br

4. Engenheiro Florestal, M.Sc., Doutorando do Programa de Pós-graduação em Engenharia Florestal, Centro de Ciências Rurais, Universidade Federal de Santa Maria, Av. Roraima, 1000, CEP 97015-900, Santa Maria (RS). vieraflorestal@yahoo.com.br

5. Engenheiro Florestal, M.Sc., Técnico do Laboratório de Ecologia Florestal, Departamento de Ciências Florestais, Centro de Ciências Rurais, Universidade Federal de Santa Maria, Av. Roraima, 1000, CEP 97015-900, Santa Maria (RS).rwitschoreck@yahoo.com.br

Recebido para publicação em 9/04/2009 e aceito em 18/05/2010 


\section{INTRODUÇÃO}

Atualmente o País vivencia um novo período de expansões no setor florestal, impulsionado pela crescente demanda e preços atrativos, especialmente associados à indústria de celulose e papel, painéis, siderurgia e carvão vegetal. As vantagens silviculturais do país são decorrentes de pesquisas desenvolvidas que revelam vantagens comparativas e competitivas (ABRAF, 2008).

A utilização de espécies exóticas, como o Pinus, o adensamento de plantas, as técnicas de preparo do solo, bem como a intensidade de colheita florestal, são algumas das práticas silviculturais que podem ser controladas mediante o conhecimento da produção de biomassa e distribuição dessas nas diversas partes da planta, incluindo-se as raízes, com vistas à manutenção da produtividade em longo prazo desses ecossistemas.

O desenvolvimento radicular é um processo muito complexo, controlado por características inerentes à própria planta $\mathrm{e}$ ao ambiente no qual ela se insere. As condições de um habitat, relativo a diversas variáveis como as inerentes ao solo, luminosidade, etc., selecionam as espécies vegetais que possuem maior tolerância às condições específicas de desenvolvimento (ANDRAE, 1978).

As pastagens formadas normalmente por gramíneas, plantas herbáceas ou arbustivas, são um dos principais tipos de vegetação que formam a cobertura do solo, totalizando $24 \%$ da área mundial. Por apresentarem a habilidade de crescer em altas densidades e de desenvolver um sistema de raízes finas, em abundância, geralmente profundas e intensamente ramificadas, dominam o solo e raras são as plantas que conseguem competir com elas por água e nutrientes (BERTONI e LOMBARDI NETO, 2005).

A maneira como ocorre o desenvolvimento das raízes, ou seja, seu hábito de enraizamento tem grande influência sobre o seu crescimento. $\mathrm{O}$ hábito de crescimento radicular determina o volume de solo ocupado pelas raízes, sendo que a densidade de raízes está associada ao grau de exploração desse solo e à capacidade de eliminação ou dominação por espécies concorrentes (GONÇALVES e MELLO, 2005).

Dentre as diversas funções do sistema radicular das plantas, destacam-se três papéis fundamentais: manter a planta fixa ao substrato, absorver água e sais minerais e produzir hormônios reguladores de crescimento (LIBARDI e LIER,
1999; RAVEN et al., 2001; WEST, 2006). Apesar da maioria das raízes terem hábito subterrâneo, muitas não o fazem, possibilitando a certos vegetais uma adaptação a condições particulares de vida, para tanto, as raízes dessas plantas adquirem morfologia e estrutura especializadas (VIDAL e VIDAL, 2000).

$\mathrm{O}$ principal fator envolvido na distribuição das raízes no solo é o genótipo da espécie, porém ele pode ser influenciado por outros fatores que estão atrelados ao solo, tais como: fertilidade, densidade, disponibilidade de oxigênio, efeito do $\mathrm{pH}$, textura, temperatura e pelas circunstâncias nas quais a espécie se desenvolve, por exemplo, competição entre árvores (GONÇALVES e MELLO, 2005).

Estudos sobre as características do sistema radicular e dos princípios da sustentabilidade nas florestas são de fundamental importância para o entendimento do equilíbrio ecológico desses ecossistemas. As informações da configuração do sistema radicular servem como subsídio para elucidar as interações fisiológicas básicas, sobretudo aquelas relacionadas com a nutrição e o balanço hídrico das árvores, fornecendo informações para a manutenção da capacidade produtiva desses sítios, sendo de extrema relevância no planejamento da atividade florestal.

O conhecimento da biomassa de raízes e a sua distribuição no solo é um importante aspecto que auxilia no entendimento das relações existentes entre elas, a parte aérea das plantas e as características edáficas, em especial no que se refere aos padrões de absorção de água e nutrientes por parte dos indivíduos (SAINJU e GOOD, 1993). Estudos mais detalhados sobre o sistema radicular das plantas, ao contrário dos estudos realizados na parte aérea, são mais trabalhosos, dificultando sua realização. Os mesmos autores indicam certo atraso na pesquisa do sistema radicular, possivelmente pelas dificuldades metodológicas e sugerem que fosse dada uma maior atenção ao assunto.

O conhecimento da dinâmica de raízes finas (comprimento e biomassa) presentes nas camadas superficiais do solo e na serapilheira é de extrema relevância. Com base nesses dados, é possível prever prováveis impactos decorrentes de atividades que propendem à diminuição do risco de incêndios, como queima controlada e gradagem, que visam à diminuição da camada do material combustível presente no piso florestal.

O presente estudo teve como objetivo quantificar e comparar a densidade e a biomassa de raízes finas $(\leq 2,0 \mathrm{~mm})$ na serapilheira e no solo,

Ci. Fl., v. 20, n. 4, out.-dez., 2010 
em um povoamento de Pinus taeda L., com 15 anos de idade e em uma área de campo na região dos Campos de Cima da Serra, RS.

\section{MATERIAL E MÉTODOS}

\section{Localização da área de estudo}

O presente estudo foi realizado no município de Cambará do Sul (Figura 1), localizado na região nordeste do estado do Rio Grande do Sul. O povoamento de Pinus taeda L. pertence à empresa Cambará S.A., estando situado nas coordenadas geográficas de $29^{\circ} 04^{\prime} 51,77^{\prime \prime}$ de latitude Sul e $50^{\circ}$ 06'27,99" de longitude Oeste, numa altitude média de 980 m em relação ao nível do mar.

Segundo a classificação de Köeppen, o tipo de clima predominante na região é o $\mathrm{Cfb}$ (temperado úmido), com uma precipitação média de $159 \mathrm{~mm}$ mensais ou $1.906 \mathrm{~mm}$ anuais, bem distribuída durante o ano, a temperatura média anual é de $15,5^{\circ} \mathrm{C}$, sendo que a média das máximas é de $20,9^{\circ} \mathrm{C}$ e a média das mínimas é de $10,9^{\circ} \mathrm{C}$, um extremo para as mínimas absolutas de $-7,2^{\circ} \mathrm{C}$, observados na estação meteorológica de Cambará do Sul, no período de 1997-2007 (INMET, 2008).

$\mathrm{O}$ solo da região pertence à Unidade de Mapeamento Bom Jesus, sendo classificado como Cambissolo Húmico alumínico típico. Predominam, nessa Unidade de Mapeamento, solos profundos, moderadamente drenados, argilosos, friáveis e desenvolvidos com base em rochas eruptivas básicas (basalto). Os solos são de cor escura, em razão do acúmulo de matéria orgânica no horizonte superficial e são fortemente ácidos, com saturação e soma de bases baixa e teores trocáveis de $\mathrm{Al}^{3} 4 \mathrm{cmol} / \mathrm{dm}^{3}$ e saturação por $\mathrm{Al}^{3} 50 \%$ (STRECK et al., 2008).

Na Tabela 1, são apresentados os valores de densidade e a caracterização textural e química do solo.

No geral, o solo apresenta fertilidade baixa a muito baixa, cabe salientar que grande parte dos nutrientes no povoamento de pinus estão imobilizados na biomassa das árvores.

Dentre as características químicas do solo, as que apresentam maior relação com o crescimento radicular estão a acidez e a deficiência de nutrientes.

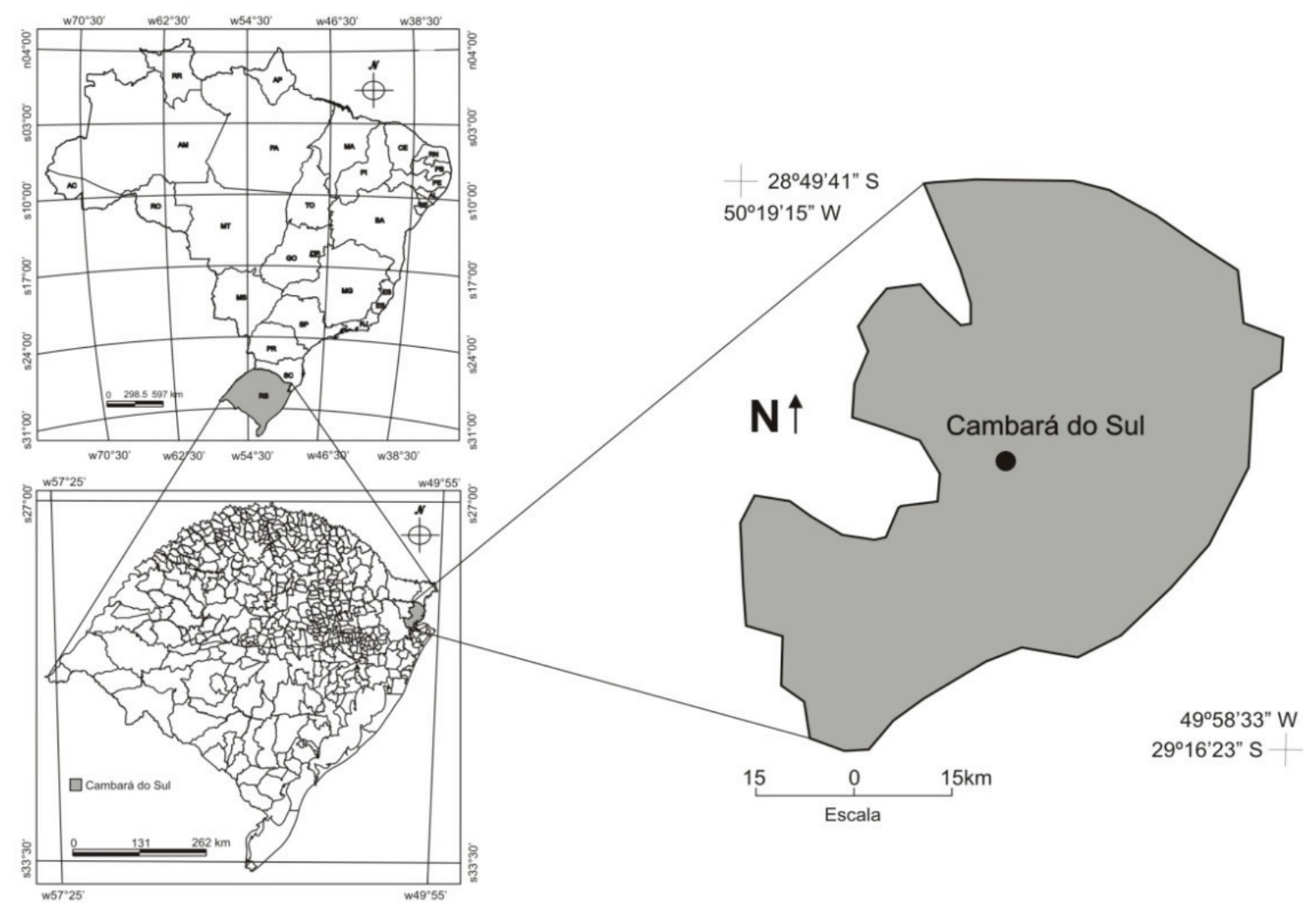

FIGURA 1: Croqui de localização do município de Cambará do Sul, RS.

FIGURE 1: Localization of Cambará do Sul, RS. 
TABELA 1: Densidade do solo e análises textural e química de amostras de solo, obtidas no Pinus taeda L. e na área de campo adjacente, no município de Cambará do Sul, RS.

TABLE 1: Bulk density, textural and chemical analysis from soil samples, obtained in Pinus taeda L. stand and in the adjacent grassland area in the city of Cambará do Sul, RS

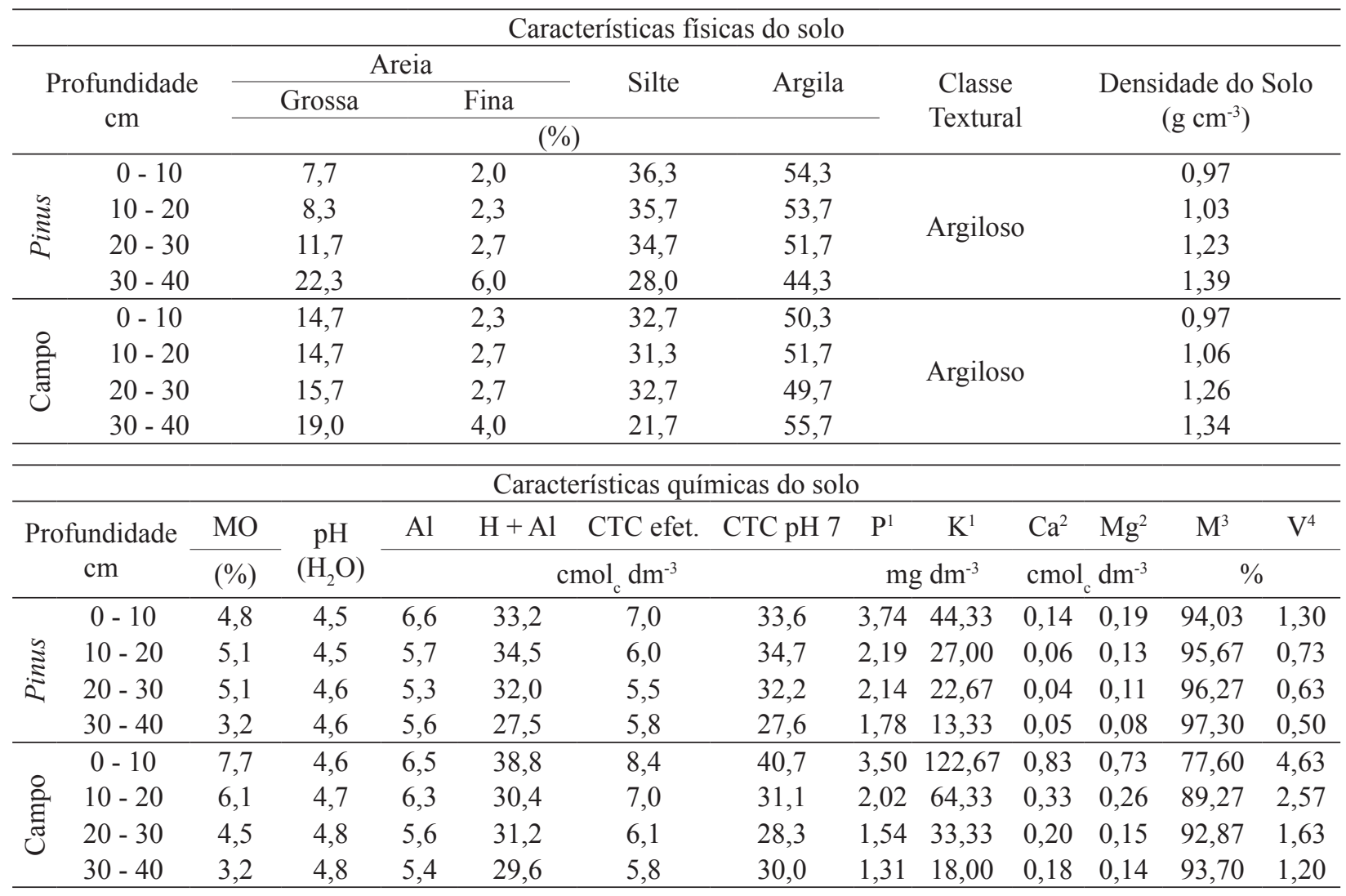

Em que: 1 - P e K disponível; 2 - Ca, Mg trocáveis; 3 - saturação de alumínio; 4 - saturação de bases. Em que: extração do solo: P e K, solução Mehlich - 1; Ca e Mg, por solução de $\mathrm{KCl}\left(1 \mathrm{~mol} \mathrm{~L}^{-1}\right)$.

Solos com pH baixo, aumentam a solubilidade do alumínio causando toxidez e consequente limitação no crescimento das raízes. A maior parte das espécies lenhosas possuem relativa tolerância a solos ácidos. Espécies do gênero Pinus, possuem a capacidade de produzir extensos sistemas radiculares, são capazes de sobreviver a severas condições de falta de nutrientes e falta de água, pois através de seu sistema radicular, conseguem explorar um grande volume de solo, concentrando suas raízes nas camadas que apresentem melhores condições edáficas ao seu desenvolvimento (PRITCHETT, 1990).

\section{Metodologia de estudo}

O povoamento de Pinus taeda L. foi implantado no ano de 1993, no período de agosto a dezembro, em área de campo, com mudas produzidas em recipientes plásticos. As sementes utilizadas para a produção de mudas foram oriundas de uma área de produção de sementes (APS) da empresa Rigesa.
Para o plantio, utilizou-se um espaçamento de $3 \mathrm{~m}$ x $2 \mathrm{~m}$, não sendo realizada nenhuma adubação, apenas foi feito o coveamento com posterior coroamento, ambos realizados manualmente. Em 1994, realizou-se uma roçada mecânica, no período entre junho e agosto procedeu-se novamente uma roçada mecânica com a finalidade de limpeza para posterior realização da desrama. A primeira desrama aconteceu de agosto a setembro de 1997, até uma altura de $1,70 \mathrm{~m}(60 \%$ da altura $)$ em $100 \%$ das árvores. Nos meses de julho a dezembro de 1999, procedeu-se a segunda desrama, até $4,5 \mathrm{~m}$ de altura em $2 / 3$ das árvores. Foram feitos dois desbastes, em $2003 \mathrm{com}$ a retirada de $120 \mathrm{~m}^{\mathrm{st}} \mathrm{ha}^{-1} \mathrm{e}$ outro em 2008, com a retirada de $130 \mathrm{~m}^{\mathrm{st}} \mathrm{ha}^{-1}$, restando 710 árvores por hectare. No momento da coleta de dados, o povoamento de Pinus encontrava-se com 15 anos de idade.

$\mathrm{Na}$ área de campo, existe a presença de gado e, consequentemente, um constante pastejo da vegetação rasteira. Normalmente, na saída 
do período de inverno, ocorrem queimadas que objetivam a limpeza e renovação da área. A vegetação presente é característica do local, sem a inserção de espécies forrageiras exóticas ou mesmo práticas de correção da fertilidade natural.

Segundo Brack et al. (2008), essa vegetação campestre é formada em especial pelas famílias Gramineae (Poaceae), Leguminosae (Fabaceae) e Compositeae (Asteraceae). Entre as espécies de Gramíneas mais comuns na fisionomia, destacam-se Andropogon lateralis (capim-caninha), Axonopus spp. (grama), Aristida spp. (capim-barba-de-bode), Erianthus trinii (macega-estaladeira), Paspalum spp. (capim), Piptochaetium montevidensis (cabelo-de-porco), Eragrostis sp. (capim-orvalho) e Panicum cf. sabulorum (capim). No que se refere a ervas de outras famílias, destacam-se as Leguminosas das quais podemos assinalar Desmodium sp., Rhynchosia sp., Crotalaria spp., Lupinus spp., etc. A família Compositeae, possui ervas de pequeno porte, como Aspilia montevidensis (margarida-do-campo), Trichocline catharinensis (cravo-do-campo), Spilanthes sp., Gamochaeta sp.. Os campos quando abandonados podem ser ocupados por vegetação arbustiva, destacando-se espécies do gênero Baccharis (Baccharis uncinella, Baccharis articulata, Baccharis dracunculifolia) e dos gêneros Eupatorium e Vernonia.

A amostragem de raízes foi realizada em novembro de 2008, pelo método de monolitos descrito por Böhm (1979), partindo da escavação manual de três monolitos de $25 \mathrm{~cm}$ x $25 \mathrm{~cm} \times$ $40 \mathrm{~cm}$, distribuídos aleatoriamente no interior do povoamento de Pinus taeda L., posicionados na diagonal entre quatro árvores e mais três monolitos na área de campo adjacente.

Inicialmente procedeu-se à abertura de uma trincheira de $40 \mathrm{~cm}$ de profundidade, na qual, promoveu-se o acesso à vista lateral do monolito. Em seguida, com o auxílio de uma moldura de ferro de $25 \mathrm{~cm} \times 25 \mathrm{~cm}$, delimitou-se a área de coleta, onde, após medida com uma régua milimétrica, foi coletada a camada superficial de serapilheira.

Posteriormente, foram eliminadas irregularidades na parede, deixando-a perfeitamente na vertical. Os monolitos ficaram subdivididos em cinco perfis geométricos de $25 \mathrm{~cm}$ x $25 \mathrm{~cm}$ x $10 \mathrm{~cm}$, compostos pela serapilheira e pelo solo nas profundidades de: $0-10,10-20,20-30,30-$ $40 \mathrm{~cm}$ (Figura 2). Na área de campo, foram coletadas apenas amostras do solo, totalizando 4 camadas por monolito.
A serapilheira e o solo coletados foram armazenados em sacos plásticos, devidamente identificados e mantidos em uma caixa térmica para posterior transporte até o Laboratório de Ecologia Florestal do Departamento de Ciências Florestais da Universidade Federal de Santa Maria. No laboratório, as amostras de solo com as raízes foram retiradas do saco plástico, colocadas em bandejas e submersas em água, para facilitar a desagregação do solo e a separação das raízes. Para a separação, utilizou-se um conjunto de duas peneiras sobrepostas; a superior com malha de $2 \mathrm{~mm}$ e a inferior de $0,5 \mathrm{~mm}$. O solo foi depositado na peneira superior, em pequenas porções, onde recebeu sucessivos jatos de água.

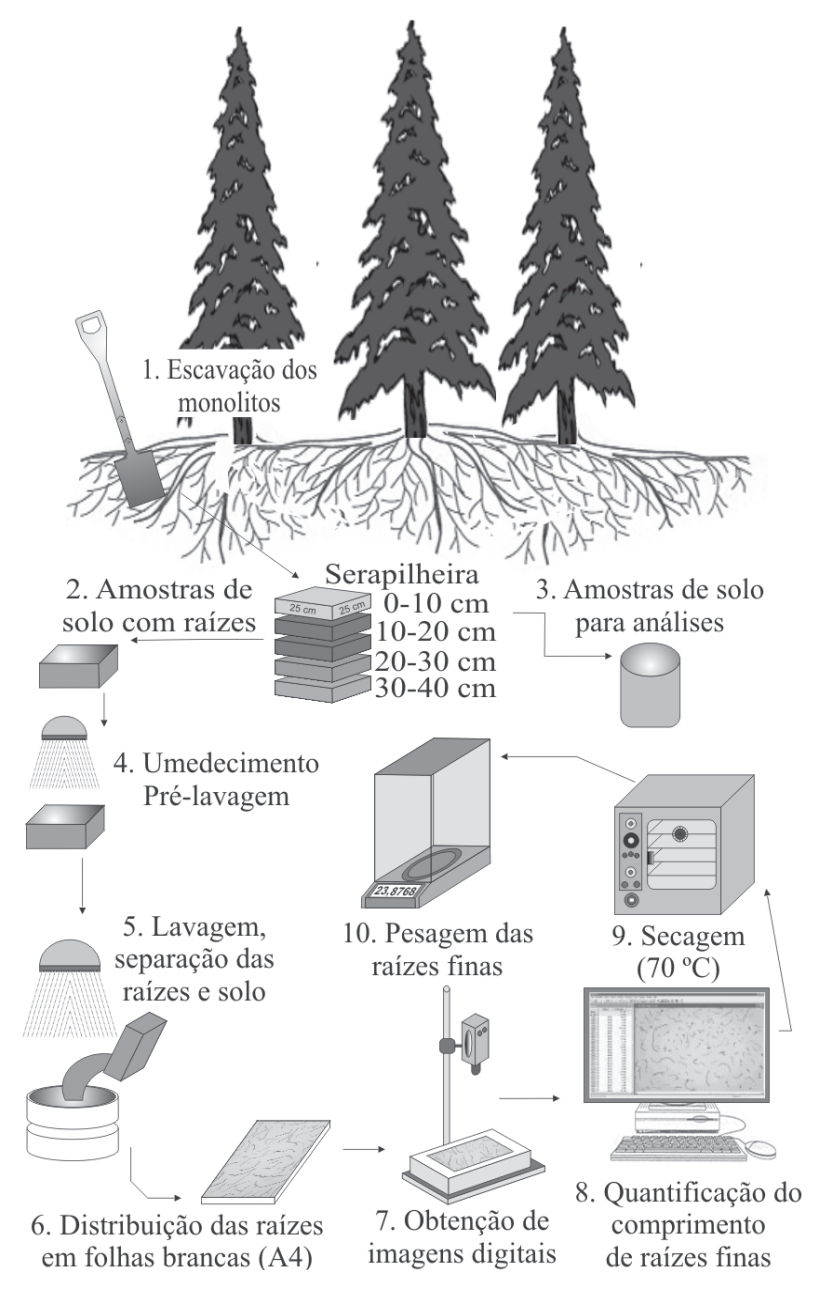

FIGURA 2: Etapas da coleta e processamento das amostras. Adaptado de Polomski e Kuhn (1998).

FIGURE 2: Sample processing and collecting phases. Adapted from Polomski and Kuhn (1998). 
Após a separação das raízes do solo, com o auxílio de um gabarito, realizou-se a devida separação das raízes finas $(\leq 2 \mathrm{~mm})$. Depois da separação, elas foram armazenadas sob refrigeração $\left( \pm 5^{\circ} \mathrm{C}\right)$, dentro de vidros com solução de álcool (10\%), devidamente fechados e identificados.

As raízes foram distribuídas manualmente sobre uma folha de papel branco no tamanho A4 $(210 \mathrm{~mm} \times 197 \mathrm{~mm})$ e por meio de uma câmera digital (Kodak DX4530, 5.0 mega pixels), apoiada em um suporte de altura fixa $(0,5 \mathrm{~m})$, obtiveram-se 2.045 imagens digitais. Com o auxilio do programa UTHSCSA, Image Tool for Windows version $3.00^{\circ}(2002)$, as imagens foram processadas. Esse programa detecta as raízes e fornece o perímetro delas. Após a quantificação do comprimento, as raízes foram secas em estufa de circulação e renovação de ar a $70^{\circ} \mathrm{C}$, por um período de 72 horas e, após, pesadas em balança analítica com $0,0001 \mathrm{~g}$ de precisão para determinação da biomassa.

Os valores encontrados para comprimento e biomassa de raízes finas nas diferentes profundidades do solo, nas duas áreas estudadas, foram submetidos à análise de variância (ANOVA one-way) ao nível de $5 \%$ de probabilidade de erro, e para a separação dos contrastes de médias utilizou-se o teste de Tukey. Todas as análises estatísticas foram realizadas com o auxilio do software STATISTICA (data analysis software system), version 7 (2004).

\section{RESULTADOS E DISCUSSÃO}

\section{Densidade de raízes finas}

A vegetação existente no campo apresenta o sistema radicular fasciculado e com raízes de finas a muito finas, característico das gramíneas, o que proporcionou os altos valores na densidade. Isso vem confirmar a alta capacidade de exploração das camadas mais superficiais do solo, em busca de água e nutrientes. Andrade (1997) destaca que a presença das raízes finas de gramíneas se dá sobretudo até a profundidade de $30 \mathrm{~cm}$. Silva et al. (2007), analisando o comprimento de raízes finas em pastagem e mata, constataram que o maior crescimento de raízes ocorreu durante o período de maior precipitação, provavelmente pela maior disponibilidade de água para as raízes, o que ratifica a opinião de autores que consideram a ausência de água um limitador ao crescimento radicular.

No pinus, a serapilheira possui uma densidade de raízes finas superior ao das camadas de $20-30 \mathrm{~cm}$ e $30-40 \mathrm{~cm}$ de profundidade. Daí a importância da interação da grande rede de raízes finas no processo de absorção de nutrientes que são disponibilizados, e na ciclagem dos minerais que se encontram nas acículas e em outros componentes orgânicos.

Navroski e Schumacher (2007), analisando o comprimento de raízes finas em uma Floresta Estacional Decidual, verificaram, para a camada de $0-15 \mathrm{~cm}$ de profundidade, mais de $40.000 \mathrm{~km} \mathrm{ha}^{-1}$ de raízes finas, decrescendo para mais de $10.000 \mathrm{~km} \mathrm{ha}^{-1}$ na profundidade de $15-30 \mathrm{~cm}$ e $5.000 \mathrm{~km} \mathrm{ha}^{-1}$ na profundidade de $30-$ $45 \mathrm{~cm}$. Da mesma forma Ceconi et al. (2008), estudando o sistema radicular de Acacia mearnsii De Wild. com quatro anos de idade, verificaram que o comprimento de raízes finas diminui com o aumento da profundidade, sendo que nos primeiros $20 \mathrm{~cm}$ encontram-se $86,59 \%$ do comprimento total de raízes finas.

Witschoreck et al. (2003), em um estudo sobre estimativa da biomassa e do comprimento de raízes finas em Eucalyptus urophylla, com 10 anos, no município de Santa Maria, RS, encontraram $27.968,9 \mathrm{~km} \mathrm{ha}^{-1}$ de comprimento médio de raízes finas no perfil de $60 \mathrm{~cm}$ de solo, sendo que, $76,1 \%$ do comprimento total dessas raízes estavam nos primeiros $30 \mathrm{~cm}$ de profundidade de solo e concentradas sobretudo na camada de $0-10 \mathrm{~cm}$.

Tratando-se de espécies florestais, vários autores constataram que a maior quantidade de raízes finas encontra-se mais superficialmente no solo e inclusive na camada de serapilheira. A presença da serapilheira é uma característica peculiar de povoamentos florestais e contribui de maneira representativa para a grande quantidade de raízes finas na camada superficial do solo e na própria serapilheira. Nesse local, as raízes encontram uma grande quantidade de nutrientes decorrentes da decomposição de acículas, galhos, cascas, entre outros componentes que formam a serapilheira, e pelas características físicas do solo que, às vezes, oferecem impedimentos para o desenvolvimento das raízes em camadas mais profundas.

$\mathrm{Na}$ Tabela 2, verificam-se os valores da densidade de raízes finas $\left(\mathrm{cm} \mathrm{cm}^{-3}\right)$ ao longo do perfil do solo. A densidade de raízes finas pode ser um fator relacionado com a característica do genótipo das plantas, como também o comportamento nutricional, o potencial produtivo e a capacidade de adaptação às condições de estresse ambiental (MARTINS et al., 2004). 
De acordo com a Tabela 2, pode-se observar que, no povoamento de Pinus, a maior densidade de raízes finas está concentrada na camada de serapilheira e no solo até $10 \mathrm{~cm}$ de profundidade, perfazendo $62,59 \%$. As camadas de $10-40 \mathrm{~cm}$ de profundidade não apresentaram diferença significativa, contudo ocorre uma considerável diminuição na densidade de raízes com o aumento da profundidade do solo. Cabe aqui salientar que, na camada de serapilheira que em média apresentou $7,33 \mathrm{~cm}$ de espessura, estão localizadas $30,30 \%$ do valor da densidade de raízes finas, ou seja, praticamente o mesmo que a soma das camadas de 10-40 cm do solo. Na área de campo, a densidade total média de raízes finas, no perfil de $40 \mathrm{~cm}$ do solo, foi de $17,43 \mathrm{~cm} \mathrm{~cm}^{-1}$, e $42,80 \%$ $\left(7,43 \mathrm{~cm} \mathrm{~cm}^{-1}\right)$ desse valor localiza-se na camada de $0-10 \mathrm{~cm}$ de profundidade. As camadas de $20-40 \mathrm{~cm}$ não diferiram estatisticamente e apresentam juntas $4,93 \mathrm{~cm} \mathrm{~cm}^{-1}$ ou $28,40 \%$ do total.

Gaitán et al. (2005), trabalhando com raízes finas de Eucalyptus globulus ssp. maidenii,

TABELA 2: Valores médios da densidade de raízes finas $\left(\mathrm{cm} \mathrm{cm}^{-3}\right)$ nas diferentes profundidades do solo, em um povoamento de Pinus taeda L. e campo na região dos Campos de Cima da Serra, município de Cambará do Sul, RS.

TABLE 2: Average values for fine root density $\left(\mathrm{cm} \mathrm{cm}^{-3}\right)$ at different soil depths, in a Pinus taeda L. stand and Grassland in Campos de Cima da Serra region, Cambará do Sul, RS.

\begin{tabular}{|c|c|c|c|c|c|c|c|}
\hline \multirow{2}{*}{\multicolumn{2}{|c|}{$\begin{array}{l}\text { Profundidade } \\
\qquad(\mathrm{cm})\end{array}$}} & \multicolumn{3}{|c|}{$\begin{array}{l}\text { Monolitos } \\
\left(\mathrm{cm} \mathrm{cm}^{-3}\right)\end{array}$} & \multirow{2}{*}{ 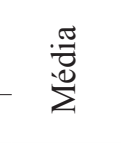 } & \multirow{2}{*}{ 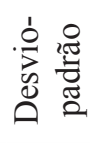 } & \multirow{2}{*}{$\begin{array}{l}\text { CV } \\
(\%)\end{array}$} \\
\hline & & $\mathrm{A}$ & $\mathrm{B}$ & $\mathrm{C}$ & & & \\
\hline \multirow{5}{*}{$\underset{\Sigma}{\vdots}$} & Serapilheira & 2,09 & 1,97 & 2,67 & $2,24 \mathrm{a}^{1}$ & 0,37 & 16,67 \\
\hline & $0-10$ & 2,58 & 1,92 & 2,68 & $2,39 \mathrm{a}$ & 0,41 & 17,26 \\
\hline & $10-20$ & 1,74 & 1,34 & 0,77 & $1,28 \mathrm{~b}$ & 0,49 & 38,12 \\
\hline & $20-30$ & 1,07 & 0,81 & 0,84 & $0,90 \mathrm{~b}$ & 0,14 & 15,86 \\
\hline & $30-40$ & 0,40 & 0,59 & 0,76 & $0,58 \mathrm{~b}$ & 0,18 & 30,92 \\
\hline \multirow{4}{*}{ 志 } & $0-10$ & 6,89 & 7,32 & 8,09 & $7,43 \mathrm{a}$ & 0,61 & 8,17 \\
\hline & $10-20$ & 5,57 & 3,90 & 5,50 & $4,99 \mathrm{~b}$ & 0,94 & 18,91 \\
\hline & $20-30$ & 2,74 & 3,93 & 1,85 & $2,84 \mathrm{bc}$ & 1,04 & 36,78 \\
\hline & $30-40$ & 2,06 & 2,99 & 1,23 & $2,09 \mathrm{c}$ & 0,88 & 41,92 \\
\hline
\end{tabular}

(1) Médias nas diferentes profundidades no Pinus e no campo, seguidas por mesma letra não diferem pelo teste de Tukey a um nível de $5 \%$ de erro. verificaram que a maior parte das raízes se encontram nos primeiros $20 \mathrm{~cm}$ de profundidade do solo, onde ocorre a ciclagem de nutrientes e as condições edáficas são mais favoráveis.

Nos estágios iniciais de desenvolvimento dos povoamentos florestais, a serapilheira está praticamente ausente, condicionando o crescimento das raízes às camadas mais profundas do solo. Com o crescimento das árvores e o aumento na produção de serapilheira, o comportamento do sistema radicular muda e passa a explorar as camadas mais superficiais do solo, onde ocorre maior ciclagem de nutrientes, provindos especialmente da decomposição da serapilheira (GONÇALVES e MELLO, 2005).

Os resultados do presente estudo assemelham-se aos obtidos por Ordinola et al. (2005) que avaliaram a biomassa e dinâmica de raízes em sistemas agroflorestais implantados em áreas de pastagens abandonadas na Amazônia central, onde foram encontradas maiores quantidades de raízes finas nos primeiros $10 \mathrm{~cm}$ de solo (60-84\% do total de raízes).

\section{Biomassa de raízes finas}

No Pinus até a profundidade de $40 \mathrm{~cm}$, foram contabilizados $3,51 \mathrm{Mg} \mathrm{ha}^{-1}$, apenas na camada de $0-10 \mathrm{~cm}$, o valor de biomassa chegou a $1,41 \mathrm{Mg} \mathrm{ha}^{-1}$, diferindo estatisticamente das demais camadas do solo e da serapilheira. A área de campo apresentou 5,63 $\mathrm{Mg} \mathrm{ha}^{-1}$, ou seja, praticamente o dobro da biomassa de raízes finas presente no Pinus. Desse total, mais da metade encontra-se na camada de $0-10 \mathrm{~cm}$ do solo, diferindo estatisticamente das demais camadas do solo (Tabela 3 ).

Os resultados de biomassa estimados se assemelham com os dados obtidos por Witschoreck et al. (2003) que, em um estudo sobre a estimativa da biomassa e do comprimento de raízes finas em Eucalyptus urophylla no município de Santa Maria, RS, encontraram, nos primeiros $30 \mathrm{~cm}$ de solo, a concentração de $72,8 \%$ da biomassa radicular média, indicando serem as raízes dessa camada as principais responsáveis pelos processos de absorção de água e nutrientes. Vanninen e Mäkelä (1999) observaram em um povoamento de Pinus sylvestris com idade de 15 anos, no extremo sul da Finlândia, uma biomassa média de raízes finas de $2205 \mathrm{~kg} \mathrm{ha}^{-1}$, em sítios de média fertilidade com presença de $4 \mathrm{~cm}$ de serapilheira. 
TABELA 3: Valores médios da biomassa de raízes finas $\left(\mathrm{kg} \mathrm{ha}^{-1}\right)$ nas diferentes profundidades do solo, em um povoamento de Pinus taeda L. e uma área de campo na região dos Campos de Cima da Serra, município de Cambará do Sul, RS.

TABLE 3: Average values for fine root biomass $\left(\mathrm{kg} \mathrm{ha}^{-1}\right)$ at different soil depths, in a Pinus taeda $\mathrm{L}$. stand and Grassland in Campos de Cima da Serra region, Cambará do Sul, RS.

\begin{tabular}{|c|c|c|c|c|c|c|c|}
\hline \multirow{2}{*}{\multicolumn{2}{|c|}{ Profundidade $(\mathrm{cm})$}} & \multicolumn{3}{|c|}{ Monolitos $\left(\mathrm{kg} \mathrm{ha}^{-1}\right)$} & \multirow{2}{*}{ Média } & \multirow{2}{*}{$\begin{array}{l}\text { Desvio- } \\
\text { padrão }\end{array}$} & \multirow{2}{*}{$\mathrm{CV}(\%)$} \\
\hline & & $\mathrm{A}$ & $\mathrm{B}$ & $\mathrm{C}$ & & & \\
\hline \multirow{6}{*}{$\begin{array}{l}\mathfrak{\Xi} \\
: \Xi \\
0\end{array}$} & Serapilheira & 505,74 & 763,97 & 1100,48 & $790,06 \mathrm{~b}$ & 298,23 & 37,75 \\
\hline & $0-10$ & 1518,80 & 1083,44 & 1634,46 & $1412,23 \mathrm{a}$ & 290,56 & 20,57 \\
\hline & $10-20$ & 809,52 & 532,13 & 524,11 & $621,92 \mathrm{~b}$ & 162,52 & 26,13 \\
\hline & $20-30$ & 463,68 & 351,20 & 453,97 & $422,95 \mathrm{~b}$ & 62,33 & 14,74 \\
\hline & $30-40$ & 150,82 & 282,46 & 372,98 & $268,75 \mathrm{~b}$ & 111,71 & 41,57 \\
\hline & Total & $3.448,56$ & 3013,20 & 4086,00 & 3515,92 & 539,56 & 15,35 \\
\hline \multirow{5}{*}{ 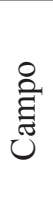 } & $0-10$ & $2.345,87$ & 3369,73 & 3535,98 & $3083,86 \mathrm{a}$ & 644,50 & 20,90 \\
\hline & $10-20$ & $1.490,24$ & 1168,16 & 1401,25 & $1353,22 b$ & 166,33 & 12,29 \\
\hline & $20-30$ & 689,23 & 980,26 & 536,29 & $735,26 \mathrm{~b}$ & 225,53 & 30,67 \\
\hline & $30-40$ & 416,34 & 582,48 & 370,75 & $456,52 \mathrm{~b}$ & 111,44 & 24,41 \\
\hline & Total & $4.941,68$ & 6100,63 & 5844,27 & 5628,86 & 608,76 & 10,81 \\
\hline
\end{tabular}

Médias nas diferentes profundidades no Pinus e no campo, seguidas por mesma letra não diferem pelo teste de Tukey a um nível de $5 \%$ de erro.

Schumacher et al. (2002), em um estudo com Araucaria angustifolia, constataram que $53,4 \%$ da biomassa total de raízes finas encontravam-se na camada de 0-30 $\mathrm{cm}$ do solo, e ainda, que entre essas camadas houve uma distribuição mais uniforme do sistema radicular. Da mesma forma, Schumacher et al. (2005), em um estudo com Pinus taeda, encontraram aproximadamente $84,6 \%$ da biomassa de raízes finas nos primeiros $30 \mathrm{~cm}$ de solo.

Lopes et al. (2006) constataram que grande parte da biomassa de raízes finas em um fragmento de Floresta Estacional Decidual, na região central do Rio Grande do Sul, está concentrada nos primeiros $10 \mathrm{~cm}$ de solo com 1,79 $\mathrm{Mg} \mathrm{ha}^{-1}$, onde perfazem $65,9 \%$ da biomassa radicular média de raízes finas. Ao passo que, com o aumento da profundidade houve considerável redução na biomassa de raízes, em virtude de estar relacionada com a matéria orgânica, maior aeração e disponibilidade de nutrientes nas primeiras camadas de solo, assim como o adensamento e presença de rochas nas camadas mais profundas.

$\mathrm{Na}$ quantificação de raízes finas realizada por Silva et al. (2007), comparativamente entre pastagem e mata natural, a biomassa média anual das raízes finas foi $2,31 \mathrm{Mg} \mathrm{ha}^{-1}$ para gramíneas, $3,52 \mathrm{Mg} \mathrm{ha}^{-1}$ para mata, sendo estimado o aporte de nutrientes ao solo, pela ação e renovação anual da maior parte das raízes finas em 16,1 e $0,65 \mathrm{~kg} \mathrm{ha}^{-1}$ para pastagem; 52,3 e $1,4 \mathrm{~kg} \mathrm{ha}^{-1}$ para mata, até a profundidade de $0-15 \mathrm{~cm}$.
A alta taxa de renovação de raízes finas consiste em uma estratégia adaptativa das árvores. Diversos estudos confirmam que os fatores que determinam o crescimento radicular são complexos e englobam condições ambientais, tanto da parte aérea como da subterrânea e sobretudo uma forte influência genética. Nesse sentido, os mesmos autores constatam que em solos com baixa disponibilidade de água e nutrientes, as árvores tendem a produzir raízes mais longas, assim explorando um maior volume de solo num menor período de tempo (GONÇALVES e MELLO, 2005).

\section{CONCLUSÕES}

Considerando-se o mesmo sítio, com profundidade média de $40 \mathrm{~cm}$ de solo, a vegetação presente na área de campo apresenta uma densidade de raízes finas $234,28 \%$ maior que a área adjacente onde se encontra o povoamento de Pinus taeda L. com 15 anos de idade.

Nas duas áreas em estudo, destacase a grande ocupação dos primeiros $10 \mathrm{~cm}$ de profundidade do solo, no Pinus taeda com 32,3\% e no campo $42,8 \%$.

A numerosa presença de raízes finas e muito finas, ou seja, menores que $2 \mathrm{~mm}$, na serapilheira do Pinus taeda, destaca a importância dessa camada no processo de ciclagem, disponibilização de nutrientes e água. 


\section{AGRADECIMENTO}

À Empresa CAMBARÁ S.A. pela disponibilização da área para coletas das amostras, especialmente nas pessoas dos Engenheiros Florestais Vandir Zancan, Leonir Barichello e do Técnico Agropecuário Evandro Viero e sua equipe de campo. À CAPES - Coordenação de Aperfeiçoamento de Pessoal de Nível Superior, pelo apoio financeiro.

\section{REFERÊNCIAS BIBLIOGRÁFICAS}

ABRAF. Anuário estatístico da ABRAF: Ano base 2007. Brasília, 90 p., 2008.

ANDRADE, A. G. Ciclagem de nutrientes e arquitetura radicular de leguminosas arbóreas de interesse para revegetação de solos degradados e estabilização de encostas. 1997. 182 f. Tese (Doutorado em Ciência do Solo)-Universidade Federal Rural do Rio de Janeiro, Rio de Janeiro, 1997.

ANDRAE, F. H. Ecologia Florestal. Santa Maria: Imprensa Universitária da UFSM, 1978. 230 p.

BERTONI, J.; LOMBARDINETO, F. Conservação do Solo. 5. ed. São Paulo: Ícone, 2005. 355 p.

BÖHM, W. Methods of studying roots systems. Berlin: Springer-Verlag, 1979. 188 p.

BRACK, P. et al. Levantamento preliminar da flora e da vegetação do vale do rio Pelotas, no município de Bom Jesus, RS. Disponível em: (http://www.inga.org.br/docs/levantamento preliminar_vegetacao_paiquere.pdf) > Acesso em: 15 de dezembro de 2008.

CECONI, D. E. et al. Biomassa e comprimento de raízes finas em povoamento de Acacia mearnsii De Wild estabelecido em área degradada por mineração de carvão. Floresta, Curitiba. v. 38, n. 1, p. 1-10, jan./mar. 2008.

GAITÁN, J. J.; PENÓN, E. A.; COSTA, M. C.. Distribución de raíces finas de Eucalyptus globulus ssp. maidenii y su relación com algumas propriedades del suelo. Ciência Florestal, Santa Maria, v. 15, n. 01, p. 33-41, jan./mar. 2005.

GONÇALVES, J. L. M.; MELLO, S. L. M. O sistema radicular das árvores. In: Nutrição e fertilização de florestas. Piracicaba: IPEF, 2005. p. 221-267.

INMET. Instituto Nacional de Meteorologia Oitavo Distrito de Meteorologia ( $8^{\circ}$ DISME). Seção de observação e meteorologia aplicada - SEMA. Porto Alegre, Relatório $\mathbf{n}^{\circ} \mathbf{0 2 7 / 2 0 0 8}$, protocolado sob n ${ }^{\circ} 4294,24 / 03 / 2008,4 p$.
LIBARDI,P.L.;LIER,Q.J.Atuaçãodosfatoresfísicos do solo no desenvolvimento do sistema radicular. In: WORKSHOP SOBRE DESENVOLVIMENTO DO SISTEMA RADICULAR: METODOLOGIAS E ESTUDO DE CASOS, 1999, Aracaju. Anais... Aracaju: Embrapa Tabuleiros Costeiros, 1999, $300 \mathrm{p}$.

LOPES, V. G. et al. Quantificação da biomassa de raízes de uma Floresta Estacional Decidual na região de Itaara, RS, Brasil. In: Jornadas Técnicas Forestales y Ambientales, 12. 2006, Eldorado. Anais... Eldorado, 2006. 1 CD ROOM.

MARTINS, L. F. da S. et al. Características do sistema radicular das árvores de Eucalyptus grandis em resposta à aplicação de doses crescentes de biossólido. Scientia Forestalis, Piracicaba, v. 65, p. 207-218, jun. 2004.

NAVROSKI, M. C.; SCHUMACHER, M. V. Quantificação do comprimento de raízes de uma Floresta Estacional Decidual na região de Itaara, RS, Brasil. Santa Maria: UFSM/FATECIENS, Departamento de Ciências Florestais. 2007. (Relatório Técnico).

ORDINOLA, J. L. E. G. et al. Biomassa e dinâmica de raízes em Sistemas Agroflorestais Implantados em Áreas de Pastagens abandonadas da Amazônia Central. Disponível em: http://www. lbaconferencia.org/cgi-bin/manaus_conf_2005/ stud05_ab_press_report.pl. Acessado em: 04/08/2005.

POLOMSKI, J.; KUHN, N. Wurzelsysteme. Bern, Stuttgart, Wien: Haupt, 1998. 290 p.

PRITCHETT, W. L. Suelos forestales: propriedades, conservación y mejoramiento. Impresso no México, 1990. $634 \mathrm{p}$.

RAVEN, H. P.; EVERT, F. R.; EICHHORN, E. S. Biologia vegetal. 6.ed Rio de Janeiro: Guanabara Koogan, 2001. 906 p.

SAINJU, U. M.; GOOD, R. E. Vertical root distribution in relation to soil properties in New Jersey Pinelands forests. Plant and Soil, v. 150, p. 87-97, 1993.

SCHUMACHER, M. V.; WITSCHORECK, R.; BARBIERI, S. J. Quantificação da serapilheira e dos nutrients em um povoamento de Araucária angustifólia (Bert.) O. Ktze na região de Quedas do Iguaçu/PR. In: SIMPÓSIO BRASILEIRO DE PÓS-GRADUAÇÃO EM ENGENHARIA FLORESTAL, 2., 2002, Viçosa. Anais... Santa Maria: UFSM, 1 CD ROOM.

SCHUMACHER, M. V. et al. Comprimento e biomassa de raízes finas em uma floresta de Pinus 
taeda L. localizada em Cambará do Sul, RS. Santa Maria: UFSM/FATECIENS, Departamento de Ciências Florestais, 2005. (Relatório Técnico). SILVA, V. F.; OLIVEIRA, F. F.; SALCEDO, I. H. Comprimento e teores de $\mathrm{N}$ e $\mathrm{P}$ em raízes finas de pastagem, mata e reflorestamento In: CONGRESSO BRASILEIRO DE CIÊNCIA DO SOLO, 31., 2007, Gramado. Anais... Gramado, 2007.

STATSOFT, Inc. (2004). STATISTICA (data analysis software system), version 7. www.statsoft. com. 2004.

STRECK, E. V. et al. Solos do Rio Grande do Sul. 2. ed, rev. e ampl. Porto alegre: EMATER/RS, UFRGS, 2008, 222 p.

UTHSCSA. Image Tool for Windows version 3.00. University of Texas Health Science Center in
San Antonio, 2002.

VANNINEN, P.; MÄKELÄ, A Fine root biomass of Scots pine stands differing in age and soil fertility in southern Finland. Tree Physiology, v. 19, p. 823830, 1999.

VIDAL, W. N.; VIDAL, M. R. R. Botânica Organografia. 4. ed, Viçosa: UFV, 2000, 124 p. WEST, P. W. Growing Plantation Forests. Springer-Verlag Berlin Heidelberg, 2006. 304 p. WITSCHORECK, R.; SCHUMACHER, M. V.; CALDEIRA, M. V. W. Estimativa da biomassa e do comprimento de raízes finas em Eucalyptus urophylla S.T. Blake no município de Santa Maria, RS. Revista Árvore, Viçosa, v. 27, n. 2, p. 177-183, 2003.

Ci. Fl., v. 20, n. 4, out.-dez., 2010 